\title{
Stearik Asit Çeşidinin Kalsit Kaplama Verimi Üzerine Etkisi
}

\author{
Metin UÇURUM ${ }^{* 1}$, Eda MALGIR ${ }^{2}$ \\ ${ }^{1}$ Bayburt Üniversitesi, Mühendislik Fakültesi, Endüstri Mühendisliği Bölümü, Bayburt \\ ${ }^{2}$ Mikrokal A.Ş, Niğde
}

Geliş tarihi: 16.02 .2017

Kabul tarihi: 31.05 .2017

Öz

Stearik asit, $\mathrm{CH}_{3}\left(\mathrm{CH}_{2}\right)_{16} \mathrm{COOH}$ formülüyle gösterilen doymuş bir yağ asididir. Birçok sanayi dalında kullanılan granül formdaki stearik asit, mikronize kalsit ürünlerinin kaplanmasında da geniş olarak kullanılmaktadır. Piyasada farklı kodlarla satılan stearik asitlerin kalsit kaplamadaki verimlerinin araştırıldığı bu çalışmada, kaplama işlemi dik karıştırmalı bilyeli değirmen kullanılarak gerçekleştirilmiştir. Beş farklı stearik asitle (C1865, C1852, C1843, C1839 ve C1837) kaplanan kalsit ürünleri önemli kalite göstergeleri olan aktive oranı, kaplama oranı, renk parametreleri $\left(\mathrm{L}^{*}, \mathrm{a}^{*}, \mathrm{~b}^{*}\right)$ ve tap yoğunluk değerleri açısından karşılaştırılmıştır. Kaplama için en uygun stearik asit tipinin ise C1865 olduğu tespit edilmiştir.

Anahtar Kelimeler: Kalsit, Kaplama, Stearik asit, Aktive oranı, Kaplama oranı, Renk parametreleri, Tap yoğunluk

\section{Effect of Stearic Acid Type on Calcite Coating Yield}

\begin{abstract}
Stearic acid is a saturated fatty acid which is represented by the formula $\mathrm{CH}_{3}\left(\mathrm{CH}_{2}\right)_{16} \mathrm{COOH}$. Granular stearic acid which is used in many industries is aslo used widely in coating of micronized calcite products. This work, which investigates the recoveries of calcite coating with stearic acids sold by different codes on the markets, was carried out for coating process by vertical stirred ball mill. The calcite products coated by five different types of stearic acids (C1865, C1852, C1843, C1839 and C1837) were compared in terms of active ratio, coating ratio, color parameters $\left(\mathrm{L}^{*}, \mathrm{a} *, \mathrm{~b} *\right)$ and tap density which are important quality indicators. The most suitable stearic acid type for calcite coating was determined as C1865.
\end{abstract}

Keywords: Calcite, Coating, Stearic acid, Active ratio, Coating ratio, Color parameters, Tap density

*Sorumlu yazar (Corresponding author): Metin UÇURUM, mucurum@bayburt.edu.tr 


\section{GíRiş}

Doymuş yağ asitleri doğal yağlarda yaygın olarak bulunurlar. Genel formülleri $\left(\mathrm{C}_{\mathrm{n}} \mathrm{H}_{2 \mathrm{n}} \mathrm{O}_{2}\right)$ olarak belirlenmiştir. Çift sayıda $\mathrm{C}$ atomu içerirler. Tek C'lu yağ asitleri bitkisel yağlarda bulunmazlar. $\mathrm{Bu}$ gruptaki en kısa zincirli yağ asidi $4 \mathrm{C}$ atomuna sahip bütirik asit iken en uzun zincirli yağ asidi 24C içeren lignoserik asittir. Bugüne kadar saptanmış en uzun zincirli doymuş yağ asidi ise 38 $\mathrm{C}$ içeren oktatriakontanoik asittir. Kısa zincirli yağ asitleri, 2-8 C içerenler, oda sıcaklığında sıvıdır. Yağ asitlerinin zincir uzunlukları arttıkça erime noktaları yükselir. Bu nedenle 8 den fazla $\mathrm{C}$ içeren yă asitleri yapısına katıldıkları yağlara katı karakter kazandırırlar [1]. Doymuş yağ asitlerinin bazı özellikleri Çizelge 1'de verilmiştir.

Çizelge 1. Doymuş yağ asitlerinin bazı özellikleri

\begin{tabular}{|c|c|c|c|}
\hline Formül & $\begin{array}{c}\text { Yaygın } \\
\text { Adı }\end{array}$ & $\begin{array}{c}\text { Molekül } \\
\text { Ağırlığ } \\
(\mathrm{g})\end{array}$ & $\begin{array}{c}\text { Erime } \\
\text { Noktası } \\
\left({ }^{\circ} \mathrm{C}\right)\end{array}$ \\
\hline $\mathrm{C}_{4} \mathrm{H}_{8} \mathrm{O}_{2}$ & Bütrik asit & 88 & $-5,6$ \\
\hline $\mathrm{C}_{6} \mathrm{H}_{12} \mathrm{O}_{2}$ & $\begin{array}{c}\text { Kapronik } \\
\text { asit }\end{array}$ & 116 & $-1,5$ \\
\hline $\mathrm{C}_{8} \mathrm{H}_{16} \mathrm{O}_{2}$ & $\begin{array}{c}\text { Kaprilik } \\
\text { asit }\end{array}$ & 144 & 16,0 \\
\hline $\mathrm{C}_{10} \mathrm{H}_{20} \mathrm{O}_{2}$ & $\begin{array}{c}\text { Kaprinik } \\
\text { asit }\end{array}$ & 172 & 31,3 \\
\hline $\mathrm{C}_{12} \mathrm{H}_{24} \mathrm{O}_{2}$ & Laurik asit & 200 & 43,6 \\
\hline $\mathrm{C}_{14} \mathrm{H}_{28} \mathrm{O}_{2}$ & $\begin{array}{c}\text { Miristik } \\
\text { asit }\end{array}$ & 228 & 54,8 \\
\hline $\mathrm{C}_{16} \mathrm{H}_{32} \mathrm{O}_{2}$ & $\begin{array}{c}\text { Palmitik } \\
\text { asit }\end{array}$ & 256 & 62,6 \\
\hline $\mathrm{C}_{18} \mathrm{H}_{34} \mathrm{O}_{2}$ & $\begin{array}{c}\text { Stearik } \\
\text { asit }\end{array}$ & 284 & 69,6 \\
\hline $\mathrm{C}_{20} \mathrm{H}_{40} \mathrm{O}_{2}$ & $\begin{array}{c}\text { Araşidik } \\
\text { asit }\end{array}$ & 312 & 75,3 \\
\hline $\mathrm{C}_{22} \mathrm{H}_{44} \mathrm{O}_{2}$ & $\begin{array}{c}\text { Behenik } \\
\text { asit }\end{array}$ & 340 & 79,9 \\
\hline $\mathrm{C}_{24} \mathrm{H}_{48} \mathrm{O}_{2}$ & $\begin{array}{c}\text { Lignoserik } \\
\text { asit }\end{array}$ & 368 & 84,1 \\
\hline
\end{tabular}

Yağ asitleri, genellikle çift sayıda karbon atomu içeren, düz zincirli ve değişik zincir uzunluğuna sahip mono bazik organik asitler şeklinde tanımlanabilir. Yağlar sabunlaştırılırsa yăg asitlerinin tuzları elde edilir. Bu tuzların asitlerle reaksiyonundan yă̆ asitleri elde edilir. Yağ asidinin alkil grubundaki bütün bağlar, sigma bağ1 yani tek bağ ise buna doymuş yağ asidi denir. Bu asitler oda sıcaklığında katı halde bulunur. C15H31-COOH palmitik asit C17H35-COOH stearik asit gibi [2].

Stearik asit, $\mathrm{CH}_{3}\left(\mathrm{CH}_{2}\right)_{16} \mathrm{COOH}$ formülüyle gösterilen doymuş bir yağ asididir. Çoğu hayvan ve bitkiden elde edilen katı-sıvı yağlarda, ekseriya gliserid stearin şeklinde bulunur. Sanayide yağların su buharıyla hidrolize uğratılmasıyla elde edilir. İçinde bir miktar palmitik ve oleik asit, yabancı madde olarak kalır. Saf madde olarak fraksiyonlu destilasyonla ayrilabilir Oleik asit, mekanik presleme yoluyla uzaklaştırılabilir. Piyasadaki stearik asit, aşağı yukarı \%40’lıktır. Stearik asit ve bileşikleri, özellikle tuzları (stearatları) ticari önemi haizdirler [3].

Kalsit; kimyasal formülü $\mathrm{CaCO}_{3}$, kristal tane boyutu $1 \mathrm{~mm}-10 \mathrm{~cm}$ arasında olan kireçtaşının yapıtaşı olan bir mineraldir. Mohs sertlik çizelgesine göre sertliği 3 ve özgül ağırlığ $20{ }^{\circ} \mathrm{C}$ 'de $2,7 \mathrm{~g} / \mathrm{cm}^{3}$ 'tür. Saf olanlarının bileşiminde $\% 56 \mathrm{CaO}, \% 44 \quad \mathrm{CO}_{2}$ ve beraberinde birlikte bulunduğu kayaç ve minerallere bağlı olarak azda olsa $\mathrm{Mg}, \mathrm{Fe}, \mathrm{Mn}, \mathrm{Zn}, \mathrm{Sr}, \mathrm{Cu}, \mathrm{Pb}, \mathrm{Co}, \mathrm{Ba}, \mathrm{Cr}$ ve $\mathrm{As}$ bulunabilir [4]. Türkiye'deki kalsit rezervlerde dikkat çeken en önemli özellikler; $\mathrm{CaCO}_{3}$ yüzdesi yüksektir, silis ve demir safsızlıkları çok düşük oranlardadır ve ögütüldükten sonraki beyazlık derecesi çok yüksektir [5].

Endüstriyel ölçekte kalsitin mikronize boyutlarda ögütülmesinde iki temel ögütme teknolojisi kullanılmaktadır, Bunlardan birincisi kuru olarak çalıştırılan konvansiyonel bilyeli değirmenler ikincisi ise karıştırmalı bilyeli değirmenlerdir (stirred mill), Söz konusu değirmenler havalı bir seperatörle kapalı devre çalıştırılarak ince/çok ince boyutlarda kalsit ürünleri üretilmektedir. Alınan ürünler farklı sanayi dallarına direkt kullanılabildiği gibi özellikle karıștırmalı bilyeli değirmen ürünleri bir yüzey modifikasyonu (kaplama) işlemi sonrasında pazarlanabilmektedir. Kalsit kaplamada Reymond değirmenler, pimli değirmenler ve 1sıtmalı karıştırmalı sistemler en 
fazla tercih edilen kaplama teknolojilerindendir. Reymond değirmende kaplama işlemi, kalsitin ve stearik asidin $\left[\mathrm{CH}_{3}\left(\mathrm{CH}_{2}\right)_{16} \mathrm{COOH}\right]$ belirli oranlarda (ortalama \%1) karıştırılarak direk değirmene beslenmesi sureti ile sürtünme enerjisinden faydalanılarak gerçekleştirilmektedir. Isıtmalıkarıştırmalı makinelerde kaplama işlemi ise 1sı ceketli kazanlarda kalsit+stearik asit (ortalama \%1) karışımının belirli sürelerde ve hızlarda karıştırılarak genellikle kesikli olarak yapılmaktadır. Her iki prosesin en önemli dezavantajı kapasite düşüklüğü ve üniform ürün eldesin de yaşanan sıkıntılardır. Kalsitin yüzey modifikasyonu (kaplaması) Dünyada ve ülkemizde en yaygin olarak stearik asit ergitme-besleme, mikronize kalsit besleme ve pimli değirmen olmak üzere üç ana üniteden oluşan pimli değirmenlerde gerçekleştirilmektedir. Pimli değirmen ile kalsit kaplama prosesinde öncelikle granül formdaki stearik asit 1 s 1 ceketli bir tankta $110-120^{\circ} \mathrm{C}$ 'de ergitilmektedir. Stearik asidin ergime sicaklığının yaklaşık $70^{\circ} \mathrm{C}$ olmasına karşın bu sıcaklıklarda ergitme yapılmasının temel nedeni viskozitenin düşürülmesidir. Buradan 1sısı korunarak pimli değirmen girişine kadar taşınan ergimiş stearik asit ile mikronize kalsit pulverize olarak pimli değirmene beslenmektedir. Elde edilen kaplı kalsit ürünleri pimli değirmenin alt çıkışından alınarak silolara beslenmektedir. $\mathrm{Bu}$ proseste ortalama $\% 0,8-1 \quad(8-10 \quad \mathrm{~kg} / \mathrm{ton})$ civarında stearik asit kullanılarak kaplama işlemleri gerçekleştirilmektedir [6]. Son yıllarda yukarda sayılan kaplama teknolojilerinin yanında mekanik-aktivasyonu baz alan karıştırmalı değirmenlerde kalsit kaplama çalışmaları da yer almaktadır.

Ürün maliyetlerinin düşürülmesinin en yaygın yollarından biri olan mineral kullanımı doğal olarak bazı sorunları beraberinde getirmiştir. Organik malzeme olan polimerler ile inorganik olan mineraller arasında yüzey gerilimi fark1 bulunmaktadır. $\mathrm{Bu}$ nedenle daha iyi fiziksel değerler elde edebilmek için minerallerin kaplanması (yüzey modifikasyonu) yoluna gidilmiştir [7]. Kaplanmış kalsitin tüketiminde kullanılan malzemelere kazandırdıkları avantajlar, hidrofobik yap1, düşük yüzey enerjisi, kolay dispersiyon, yüksek homojenizasyon, mukavemet artışı, kimyasal dayanım, organik ortamlara uyumluluk, daha parlak ve düzgün yüzey, daha az kalıp aşınması ve makine verimliliklerinde artış olarak sıralamak mümkündür [8].

Son yıllarda mikronize kalsit ögütme tesislerinde, stearik asit çeşitlerinin kaplama verimleri araştırma konusu olmuş durumdadır. Bu bağlamda, sunulan çalışmada; C1865, C1852, C1843, C1839 ve C1837 olmak üzere beş farklı stearik asit tipinin kalsit kaplama verimleri araştırılmıştır. Deneysel çalışmalar, dik karıştırmalı bilyeli değirmende yapılmış olup elde edilen kaplı kalsit ürünlerinin aktive oranlarına, kaplama oranlarına, renk parametreleri değerlerine ve tap yoğunluklarına bakılmıştır.

\section{MATERYAL VE METOT}

\subsection{Materyal}

Deneylerde, $\quad d_{10}=0,80 \mu \mathrm{m}, \quad d_{50}=2,45 \quad \mu \mathrm{m} \quad$ ve $\mathrm{d}_{97}=8,81 \mu \mathrm{m}$ boyut dağılımına sahip mikronize kalsit numunesi kullanılmıştır (Şekil 1). Söz konusu numuneye ait XRF sonuçları ise Çizelge 2'de verilmiştir. XRF sonuçlarına bakıldığı zaman kalsit cevherinin oldukça temiz olduğu ve safsızlık içermediği görülmektedir. Zira mikronize kalsitte en önemli safsızlık olarak kabul edilen demiroksit içeriği sadece $\% 0,05$ oranında kendini göstermektedir. Bununla birlikte yine istenmeyen elementlerden olan $\mathrm{Si}$ içeriği de yine sadece $\% 0,70$ civarındadır. Ayrıca, yapılan XRD analizi sonucunda ise kalsit cevherinin sadece kalsit mineralinden oluştuğu (ASTM No:86-2334) yani tamamen saf bir cevher olduğu anlaşılmaktadır. Bunlarla birlikte deneylerde kullanılan mikronize kalsit ürününe ait $L^{*}, a^{*}$ ve $b^{*}$ değerleri sırası ile 98,84, -0,01 ve 0,67 olarak tespit edilmiştir. Ayrıca deneylerde kullanılan mikronize kalsit ürünün tap yoğunluğu $0,892 \mathrm{~g} / \mathrm{cm}^{3}$ olarak tespit edilmiştir.

Çizelge 3'de deneysel çalışmalarda kullanılan beş çeşit stearik asit çeşidinin C12, C14, C16 ve C18 içerikleri verilmiştir. Çizelgeden anlaşılacağı üzere stearik asit çeşidinin kodlarında mevcut C18 sayısal değeri stearik asit olduğunu gösterirken diğer iki rakam stearik asit oranını vermektedir. Örneğin C1865 kodlu kimyasalın ortalama \%65 
stearik asit içerdiğini göstermektedir. Diğer bir deyişle Çizelge 1 baz alındığında, C1865 stearik asit tipinin maksimum \%1 Laurik asit, maksimum $\% 2$ Miristik asit, \%34 Palmitik asit ve \%65 stearik asit içerdiği söylenebilir.

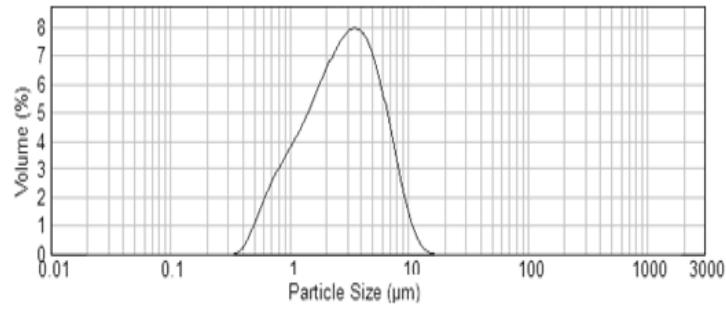

Şekil 1. Çalışmalarda kullanılan numunesine ait tane irilik dağılımı

Çizelge 2. Mikronize kalsit numunesine ait XRF sonuçları

\begin{tabular}{|c|c|}
\hline Bileşik & $\%$ \\
\hline $\mathrm{SiO}_{2}$ & 0,70 \\
\hline $\mathrm{CaO}$ & 54,85 \\
\hline $\mathrm{MgO}$ & 0,47 \\
\hline $\mathrm{Fe}_{2} \mathrm{O}_{3}$ & 0,05 \\
\hline $\mathrm{Al}_{2} \mathrm{O}_{3}$ & 0,05 \\
\hline $\mathrm{Na}_{2} \mathrm{O}$ & 0,01 \\
\hline $\mathrm{K}_{2} \mathrm{O}$ & 0,02 \\
\hline $\mathrm{SO}_{3}$ & $<0,01$ \\
\hline Ateş Zayiat1 & 43,20 \\
\hline
\end{tabular}

Çizelge 3. Stearik asit çeşitlerinin C12, C14, C16 ve $\mathrm{C} 18$ içerikleri

\begin{tabular}{|c|c|c|c|c|}
\hline $\begin{array}{c}\text { Stearik Asit } \\
\text { Çeşidi }\end{array}$ & $\begin{array}{c}\text { C12 } \\
(\%)\end{array}$ & $\begin{array}{c}\text { C14 } \\
(\%)\end{array}$ & $\begin{array}{c}\text { C16 } \\
(\%)\end{array}$ & $\begin{array}{c}\text { C18 } \\
(\%)\end{array}$ \\
\hline C1865 & $\operatorname{max~1~}$ & $\max 2$ & 34 & 65 \\
\hline C1852 & $\max 1$ & $\max 2$ & 45 & 52 \\
\hline $\mathrm{C} 1843$ & $\max 1$ & $\max 2$ & 55 & 43 \\
\hline $\mathrm{C} 1839$ & $\max 1$ & $\max 2$ & 60 & 39 \\
\hline $\mathrm{C} 1837$ & $\max 1$ & $\max 2$ & 62 & 37 \\
\hline
\end{tabular}

\subsection{Metot}

Kaplama çalışmaları, 150x170 mm boyutlu laboratuvar tipi dik karıștırmalı bilyeli değirmen kullanılarak gerçekleştirilmiştir (Şekil 2). Öğütücü ortam olarak $\mathrm{d}_{\mathrm{Al}}=3,5-4 \mathrm{~mm}$ alümina bilyeler kullanılmıştır. Bilye özellikleri ise Çizelge 4'de verilmiştir. Kaplama işleminde değirmende alümina bilyeler kullanılarak demir kirlenmesinin önüne geçilmeye çalışılmıştır.

Çizelge 4. Öğütücü ortam olarak kullanılan alümina bilyelerin özellikleri

\begin{tabular}{|c|c|c|}
\hline Bileşim & $\begin{array}{c}\text { Özgül } \\
\text { ağırlık } \\
\left(\mathrm{kg} / \mathrm{m}^{3}\right)\end{array}$ & Sertlik \\
\hline $\mathrm{Al}_{2} \mathrm{O}_{3}(95 \%)+\mathrm{SiO}_{2}(5 \%)$ & 3600 & $>1200 \mathrm{HV}$ \\
\hline
\end{tabular}

Aktive Oranı belirli bir miktar (5 gram'a kadar) kaplı kalsit numunesi 200-300 cc suda yüksek hızda karıştırılması sonrası yüzen ve batan miktar esas alınarak Eşitlik 1'de verilen formül yardımı ile hesaplanmaktadır [9].

$\mathrm{AR}(\%)=[\mathrm{Mp} /(\mathrm{Mp}+\mathrm{Mt})] * 100$

Burada,

Mp: Yüzen ürün miktarı $(\mathrm{g})$; Mt: Batan ürün miktar1 (g)

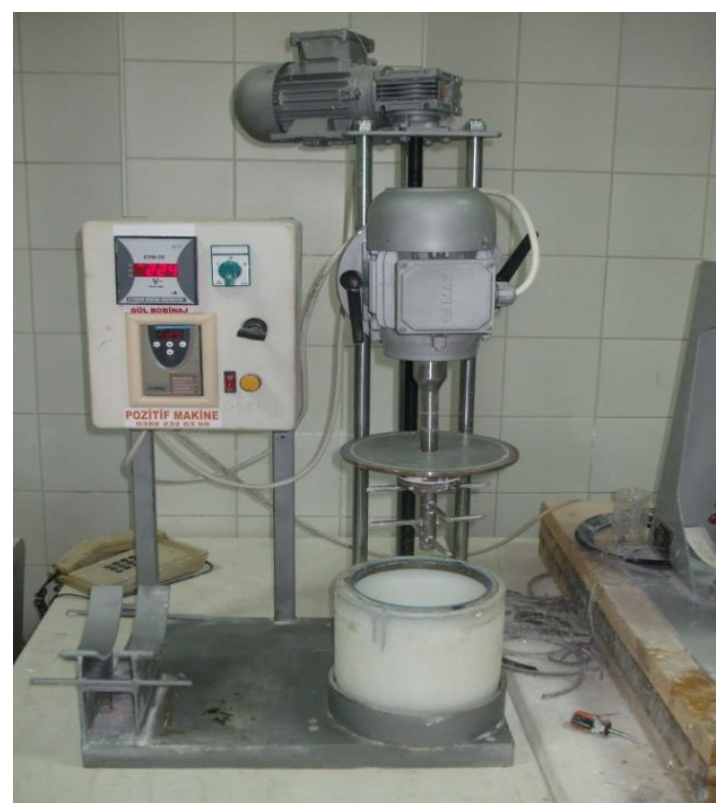

Şekil 2. Deneylerde kullanılan dik karıștırmalı bilyeli değirmen

$\mathrm{Bu}$ oran özellikle kaplı kalsit üreticileri ve tüketicileri tarafından ürün kalitesin en önemli göstergesi olarak kabul edilmekte olup bu yaklaşım akademik çalışmalarda da 
desteklemektedir [10, 11]. Endüstride kullanılan kaplı kalsit ürünlerinin \%100'e yakın bir aktive oranı değerine sahip olması istenmektedir.

Kaplı kalsitin en önemli özelliklerinden birisi de renk değerleridir. Bunlar $\mathrm{L}^{*}, \mathrm{a}^{*}, \mathrm{ve} \mathrm{b}^{*}$ parametreleridir. CIEL*a*b* renk sisteminde; renklerdeki farklılıklar ve bunların yerleri $L^{*}, a^{*}, b^{*}$ renk koordinatlarına göre tespit edilmektedir. Burada, $L^{*}$ siyah-beyaz (siyah için $L^{*}=0$, beyaz için $L^{*}=100$ ) ekseninde, $a^{*}$ kırmızı-yeşil (pozitif değeri kırmızı, negatif değeri yeşil) ekseninde, $b^{*}$ ise sarı-mavi (pozitif değeri sarı, negatif değeri mavi) ekseninde yer almaktadır [12, 13]. Deneylerden elde edilen ürünlerin renk parametre değerleri Datacolor Elrepho 450x beyazlık ölçüm cihazından elde edilmiştir (Şekil 3).

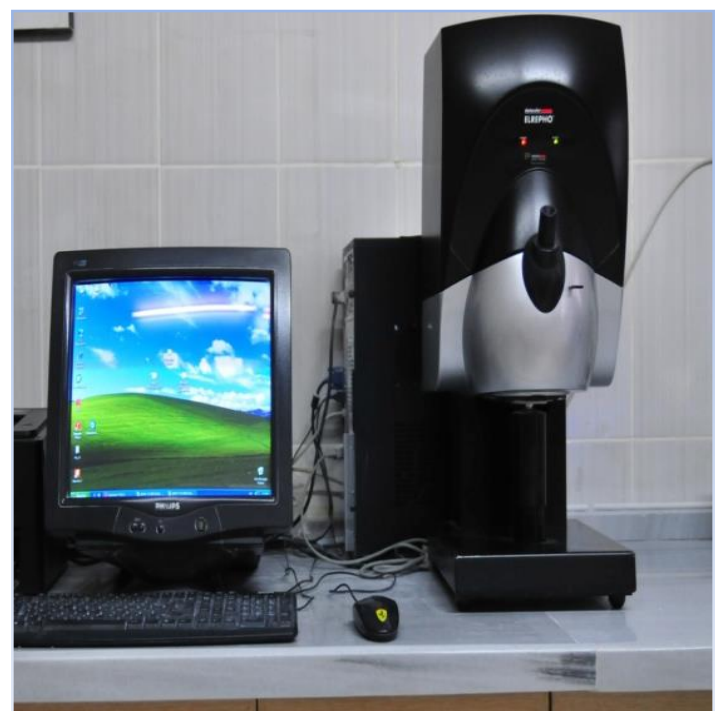

Şekil 3. Datacolor Elrepho 450x beyazlık ölçüm cihaz1

Kaplama oranı mikronize kalsit tesislerinde kaplı kalsit ürünlerinin kalite kontrol amaçlı yapılan bir testtir. Endüstriyel ölçekte mikronize kalsit ürünleri genellikle stearik asit ile kaplanması ve bu kimyasalın ortalama $383^{\circ} \mathrm{C}$ buharlaşma isısına sahip olması sebebi ile kaplanmış kalsitin nemi alındıktan sonra $400^{\circ} \mathrm{C}$ de kül firınında bir saat bekletildikten sonra kütle kaybı hesabına dayalı olarak kaplama oranı değeri hesaplanmaktadır (Eşitlik 2).
Elde edilen sonuçlar kaplamada kullanılan ton başına stearik asit baz alınarak değerlendirilmektedir.

Kaplama oranı: [(Toplam kütle kayb1/Numune miktar1)]x100

Mikronize kalsit sektöründe mikronize boyutlara öğütülen ve kaplanan kalsitin yığın yoğunluğu sanayide Tap yoğunluk olarak adlandırılmakta olup bunun ölçülmesinde Şekil 4'de verilen Autotap tap density tipi cihazlar tercih edilmektedir. $\mathrm{Bu}$ testte, ağırlığı alınmış (M) ortalama $100 \mathrm{cc}$ numune dereceli bir silindire konulduktan sonra Autotap tap density tipi cihazına yerleştirilerek 1250 vurum işlemi gerçekleştirilir. Daha sonra yeni hacim $\left(\mathrm{V}_{\text {son }}\right)$ okunarak $\mathrm{g}_{\text {tap }}=\mathrm{M} / \mathrm{V}_{\text {son }}$ formül ile tap yoğunluk $\left(\mathrm{g} / \mathrm{cm}^{3}\right)$ elde edilmektedir.

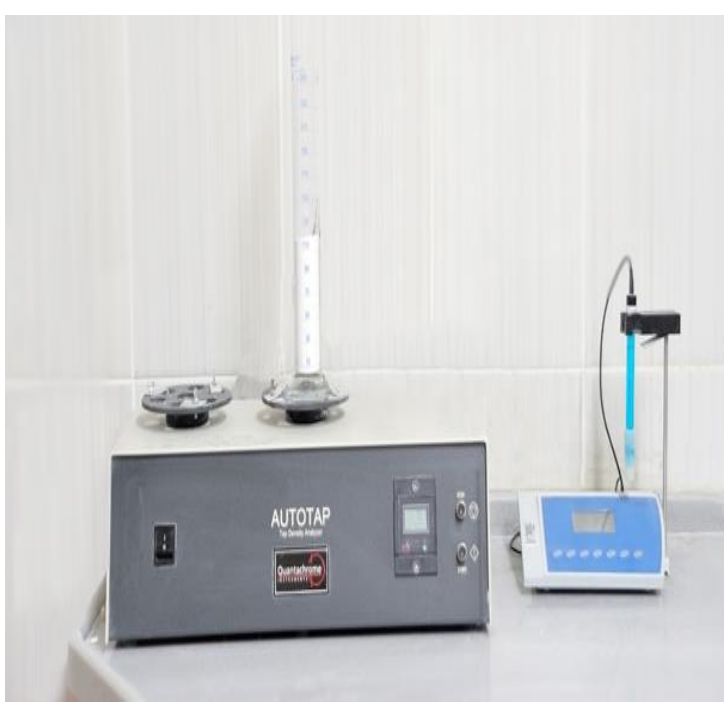

Şekil 4. Autotap tap density tap yoğunlukölçer

\section{SONUÇLAR}

Deneysel çalışmalar Çizelge 5'de verilen şartlarda gerçekleştirilmiştir. Kaplama çalışmalarında kullanilan mikronize kalsit numunesinin $\% 0,5, \% 0,8$ ve $\% 1$ oranlarında stearik asit kullanılmıştır. Elde edilen deney ürünleri üzerinden yukarda siralanan testler (aktive oranı, kaplama oranı, tane iriliği dağılımı, beyazlık, tap 
yoğunluk) yapılmıştır. Deney sonuçları ise Şekil 5 , 6 ve Çizelge 6, 7'de verilmiştir.

Çizelge 5. Kaplama çalışmalarında kullanılan deney şartları

\begin{tabular}{|c|c|}
\hline Değişkenler & \\
\hline Kimyasal miktarı (\%) & $0,5,0,8,1,0$ \\
\hline Karıştırma hızı (d/dk) & 750 \\
\hline Kaplama süresi (dk) & 10 \\
\hline Bilye doluluk oranı (\%) & 40 \\
\hline Kalsit bilye oranı & $1: 5$ \\
\hline
\end{tabular}

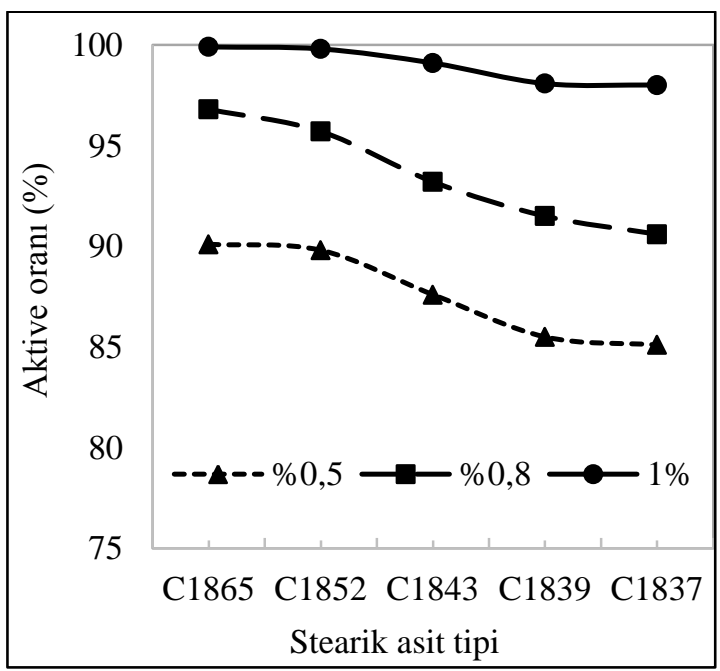

Şekil 5. Elde edilen ürünlerin aktive oranları

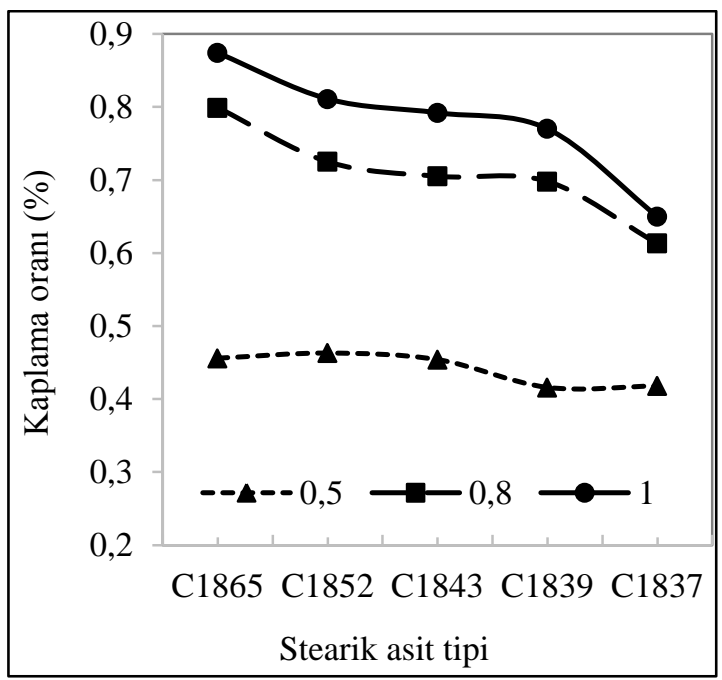

Şekil 6. Elde edilen ürünlerin kaplama oranları
Çizelge 6. Elde edilen ürünlerin renk parametre değerleri

\begin{tabular}{|l|c|c|c|}
\hline \multirow{2}{*}{$\begin{array}{l}\text { Stearik Asit } \\
\text { Cinsi }\end{array}$} & \multicolumn{3}{|c|}{$\% 0,5$} \\
\cline { 2 - 4 } C1865 & L* & $\mathrm{a}^{*}$ & $\mathrm{~b}^{*}$ \\
\hline C1852 & 98,18 & 0,04 & 1,03 \\
\hline C1843 & 98,11 & 0,05 & 1,05 \\
\hline C1839 & 95,09 & 0,04 & 1,04 \\
\hline C1837 & 98,18 & 0,04 & 1,04 \\
\hline Stearik Asit & & $\% 0,8$ \\
\cline { 2 - 4 } Cinsi & L* & $\mathrm{a}^{*}$ & $\mathrm{~b}^{*}$ \\
\hline C1865 & 97,96 & 0,02 & 0,93 \\
\hline C1852 & 98,21 & 0,02 & 0,93 \\
\hline C1843 & 98,08 & 0,02 & 0,95 \\
\hline C1839 & 98,15 & 0,03 & 1,03 \\
\hline C1837 & 98,2 & 0,05 & 1,07 \\
\hline Stearik Asit & & \multicolumn{3}{|c|}{$\% 1$} & 1,06 \\
\cline { 2 - 4 } Cinsi & L* & $\mathrm{a}^{*}$ & $\mathrm{~b}^{*}$ \\
\hline C1865 & 98,11 & $-0,02$ & 0,81 \\
\hline C1852 & 97,92 & $-0,01$ & 0,86 \\
\hline C1843 & 97,93 & 0 & 1,01 \\
\hline C1839 & 97,91 & 0 & 1,01 \\
\hline C1837 & 97,45 & $-0,01$ & 1,03 \\
\hline
\end{tabular}

Şekil 5 incelendiğinde, çalışılan her bir stearik asit oranı (\%0,5-0,8-1) için C1865'den C1837'ye doğru aktive oranlarında lineer bir azalmanın olduğu görülmektedir. Diğer bir deyişle bu sonuç, kimyasalın stearik asit içeriği ile doğru orantılı olarak aktive oranın iyileştiği anlamını da taşımaktadır. Bununla birlikte, mikronize kalsitin kaplanmasında \%1 stearik asit oranının en ideal olduğu da ortaya konmuştur. Yapılan çalışmalarda, C1865 stearik asit tipinin \%1 oranında kullanılarak elde edilen kaplı kalsit ürünü yaklaşık \%100 aktive oranına sahip olduğu da görülmektedir. Bu elde edilen sonuç mikronize kalsit ürünün hemen 
hemen \%100'nün hidrofilik yapıdan hidrofobik yapıya geçtiği anlamını da taşımaktadır. Bu sonuçları Şekil 6'da verilen kaplama oranı deney sonuçları da desteklemektedir. Yine burada C1865 yaklaşık \%1 kaplama oranı ile en iyi sonucu vermiştir. Elde edilen ürünlerin renk değerleri incelendiğinde (Çizelge 6) kullanılan stearik asit cinsinin ve oranının renk parametreleri üzerinde çok büyük değişikliklere neden olmadığı görülmektedir. Deneylerde kullanılan mikronize kalsit ürününe ait $\mathrm{L}^{*}, \mathrm{a}^{*}$ ve $\mathrm{b}^{*}$ değerleri ile $(98,84,-0.01$ ve 0,67$)$ elde edilen kaplı ürünlere ait renk parametrelere değerleri karşılaştırıldığında en önemli değişikliğin sarılık değerini gösteren $b^{*}$ parametresinde olduğu görülmektedir. $\mathrm{Bu}$ değer mikronize kalsit ürününde 0,67 iken kaplı kalsit ürünlerinde 1,07'ye kadar çıkmıştır. Endüstriyel ölçekte kaplı kalsit ürünleri incelendiğinde bu artışın normal olduğu söylenebilmektedir. Aktive ve kaplama oranları baz alınarak en iyi sonucun elde edildiği C1865 stearik asit tipinin ve \%1'lik stearik asit oranın kullanılarak elde edilen kaplı kalsit ürününün $\mathrm{L}^{*}$ değerinin 98,11 , a* değerinin $-0,02$ ve $b^{*}$ değerinin 0,81 olduğu görülmektedir. Besleme malına göre beyazlık değerindeki azalma ve $b^{*}$ değerlerinde ise artış görülmektedir. Daha önce belirtildiği üzere bu normal karşılanacak bir sonuç olarak değerlendirilmektedir. Çizelge 7'de tap yoğunluk değerleri incelendiğinde, elde edilen ürünlerin söz konusu özellikleri arasında kayda değer bir farkın olmadığı görülmektedir. Aktive ve kaplama oranları baz alınarak en iyi sonucun elde edildiği C1865 ve \%1'lik stearik asit oranı ürününün tap değeri 1,0596 olarak tespit edilmiştir.

Çizelge 7. Elde edilen ürünlerin tap yoğunluk değerleri

\begin{tabular}{|c|c|c|c|}
\hline $\begin{array}{c}\text { Stearik } \\
\text { Asit Cinsi }\end{array}$ & $\% 0,5$ & $\% 0,8$ & $\% 1$ \\
\hline $\mathrm{C} 1865$ & 1,0852 & 1,0665 & 1,0596 \\
\hline $\mathrm{C} 1852$ & 1,0896 & 1,0669 & 1,0598 \\
\hline $\mathrm{C} 1843$ & 1,0902 & 1,0752 & 1,0606 \\
\hline $\mathrm{C} 1839$ & 1,0959 & 1,0805 & 1,0656 \\
\hline $\mathrm{C} 1837$ & 1,9630 & 1,0855 & 1,0703 \\
\hline
\end{tabular}

\section{4. ÖNERILER VE TARTIŞMA}

Son y1llarda mikronize kalsit öğütme tesislerinde kaplama işlemi anahtar proses konumuna gelmiş durumdadır. Zira kaplı kalsit ürün satışları mikronize ürün satışlarından daha fazla bir oranı yakalamıştır. $\mathrm{Bu}$ bağlamda kaplamda en fazla kullanılan yağ asidi olan stearik asit çeşitlerinden hangisinin tercih edileceği işletmelerde soru işareti olarak araştırılmaya muhtaç bir konu haline almıştır. $\mathrm{Bu}$ nedenle, sunulan çalışma ile bu problemin çözümüne katkı sağlanması amaçlanmıştır. Kalsit kaplama çalışmalarında kullanılan C1865, C1852, C1843, C1839 ve C1837 olmak üzere beş farklı stearik asit tipinin kaplı kalsitte önemli bir gösterge olan aktive oranı ile birlikte kaplama oran1, renk parametreleri ve tap yoğunluklar kullanılarak dik karıştırmalı bilyeli değirmende karşılaştırılmalı deneysel çalışmalar yapılmıştır. Özellikle aktive oranı ve kaplama oranı baz alındığında en iyi sonucun C1865 stearik asit tipinde elde edildiği sonucuna ulaşılmıştır. Bu çalışmanın devamı olarak stearik asit dışında farklı yağ asitlerinin kalsit kaplanmasındaki verimlerinin araştırılmasına da ihtiyaç vardır.

\section{TEŞEKKÜR}

$\mathrm{Bu}$ çalışma; Mikrokal Kalsit Sanayi Limited Şirketi bünyesinde TÜBİTAK destekli 3100352 nolu TEYDEP projesi ile yaptırılmıştır. Yazarlar desteklerinden dolayı TÜBİTAK'a ve Mikrokal Kalsit Sanayi Limited Şirketi'ne teşekkür ederler.

\section{KAYNAKLAR}

1. http://www.kimyaevi.org, 10.02.2016.

2. Megep, 2013. Yağlar ve Yağ Analizleri, Ankara. http://megep.meb.gov.tr, 17.02.2017

3. http://www.hammaddeleransiklopedisi.com, 10.02.2016.

4. Şahin, N., 1978. Türkiye Kalsit Olanakları ve Kalsitin Endüstriyel Hammadde Olarak Hazırlanması, Bitirme Çalışması, Hacettepe Üniversitesi, Ankara.

5. Devlet Planlama Teşkilatı (DPT) 2001. Sekizinci Beş Yıllık Kalkınma Planı, Madencilik ÖİK Raporu Endüstriyel 
Hammaddeler Alt Komisyonu Genel Endüstri Mineralleri (Asbest-Grafit-Kalsit-FluoritTitanyum Çalışma Grubu Raporu) 2618- ÖİK: 629, Ankara.

6. Uçurum, M., 2004. Kaplı Kalsit Üretimi ve Ürün Özellikleri, MT Türkiye, Y11:3, Sayı:6, s. $1-10$.

7. Gema Elektro Plastik. 2009. Kalsiyum Karbonat $\left(\mathrm{CaCO}_{3}\right)$ Dolgulu Ürünler, Basım Yeri: Yunus Matbaacılık Ltd. Sti. İstanbul.

8. http://www.hisarmaden.com/tur/index.php? option=com_content\&task=view\&id=17\&Ite, 11.11.2014.

9. Sheng, Y., Zhou, B., Zhao, J., Tao, N., Yu, K., Tian, Y., Wang. Z., 2004. Influence of Octadecyl Dihydrogen Phosphate on the Formation of Active Super-Fine Calcium Carbonate, Journal of Colloid and Interface Science 272, 326-329.

10. Wu W., Lu S.C., 2003. Mechano-Chemical Surface Modification of Calcium Carbonate Particles by Polymer Grafting, Powder Technol. 137, 41-48.

11. Ding H., Lu S.C., Deng Y.X., Du C.X., 2007. Mechano-Activated Surface Modification of Calcium Carbonate in Wet Stirred Mill and its Properties, Trans. Nonferrous Met. Soc. China 17, 1100-1104.

12. Oliver, J.R., Blakeney, A.B., Allen, H. M., 1992. Measurement of Flour Color in Color Space Parameters: Cereal Chem, 69, 546-551.

13. McGuire, R. G.1992. Reporting of Objective Color Measurements: HortScience, 27, 1254-1255. 